\title{
Risk and health-promoting behaviours in adolescents with different temperamental profiles
}

\begin{abstract}
BACKGROUND
While temperamental traits have been shown to be an important predictor of risk behaviour, much less attention has been paid to health-promoting behaviour. The concept of temperamental profiles as individual compositions of traits allows the formulation of predictions concerning differences in such behaviours. This study aimed to find differences in engaging in risk and health-promoting behaviours in adolescents with different temperamental profiles that represented individuals differing in stimulation regulation.
\end{abstract}

\section{METHODS}

A group of 345 adolescents, 196 female and 149 male aged 1819 years, completed questionnaires measuring engagement in risk and health-promoting behaviours as well as temperamental traits. Participants were then assigned by means of cluster analysis to four groups with different temperamental trait profiles. Aggregated scores of risk and health behaviours were used based on the frequency of occurrence.

\section{RESULTS}

Adolescents characterised by a non-resilient temperamental profile engaged both in risk and health-promoting behaviours less frequently than those characterised by other profiles. Gender-related differences in health promoting behaviours were also found. Female participants reported engaging in health-promoting behaviours more frequently than male participants.

\section{CONCLUSIONS}

Compositions of temperamental traits identified by means of cluster analysis can explain to some extent differences in engaging in risky and health-promoting behaviours in adolescents.

\section{KEY WORDS}

risk behaviours; heath-promoting behaviours; temperament; adolescents 


\section{BACKGROUND}

Risk behaviours in adolescents occur quite frequently (Feldstein \& Miller, 2006), but since not all young adults engage in such behaviours, numerous empirical studies have attempted to identify the psychological qualities that differentiate those who do from those who do not engage in such behaviour. While some studies focussed on cognitive factors (Beyth-Marom, Austin, Fischhoff, Palmgran, \& Jacobs-Quadrel, 1993), a considerable amount of research targeted individual differences such as temperament and personality traits. Identifying individual traits that make a person more inclined to engage in risky behaviours can be useful in prevention programmes.

Numerous studies have indicated the individual traits responsible for risky behaviours in adolescents: sensation or novelty seeking (Maslowsky, Buvinger, Keating, Steiberg, \& Cauffman, 2011; Brejard, Bonnett, \& Pedinielli, 2012; Cooper, Wood, Orcutt, \& Albino; 2003, Arnett, 1990a, 1990b); negative emotionality (Yucel et al., 2015, Caspi et al., 1997); and impulsivity/aggression (Stevens, Plumert, Cremer, \& Kearney, 2013; Rudasill, Reio, Stipanovic, \& Taylor, 2010; Cooper et al., 2003; Caspi et al., 1997). There is a strong agreement among researchers that multiple factors underlie risky behaviours (Feldstein \& Miller, 2006); therefore, multiple personality/temperament traits were usually analysed (White, Lejues, de Wit, 2007; Cooper et al., 2003; Caspi et al., 1997). Aggressive adolescents who scored lower on traditionalism, harm avoidance, control and social closeness were more likely to engage in health-risk behaviours (Caspi et al., 1997) while those characterised by high levels of sensation seeking, neuroticism, aggression, anger, and impulsivity were generally more inclined to engage in risky behaviours (Cooper et al., 2003). According to White, Lejues, and de Wit (2007), adolescents characterised by high reward sensitivity were more inclined to amphetamine-induced risk taking, while traits of negative emotionality and impulsivity were not relevant. Moreover, it has been suggested that research on temperamental predictors of risky behaviours should focus on multiple rather than single behaviours (Feldstein \& Miller, 2006).

Much less attention has been given to the temperamental factors responsible for health-promoting behaviours; however, two studies should be mentioned. The first studied athletes and showed some relationships between such behaviours and personality traits of neuroticism and extraversion, but there were no significant relationships with temperament because it was not related to health-promoting behaviours (Pisarek, Guszkowska, Zagorska, \& Lenartowicz, 2011). The second focused on children's oral care behaviours and showed temperamental traits negatively related to health care behaviours (Virgo-Milton et al., 2015).
The present study concerns temperamental correlates of risk and health-promoting behaviours in adolescents, while acknowledging that there are other significant factors, such as personal expectancies concerning effects of behaviours or pressures of a peer group, which, together with individual traits, influence such behaviours. Most studies mentioned earlier used particular temperament traits as variables either separately or as aggregated scores (White, Lejues, \& de Wit, 2007; Cooper et al., 2003; Caspi et al., 1997). This study was based on an approach in which individual profiles of traits, identified by means of cluster analysis, were used as predictors of such behaviours.

Temperamental traits distinguished in Regulative Theory of Temperament (Strelau \& Zawadzki, 1993) were chosen as predictors of risky and health-promoting behaviours. Namely six traits with the status of first-order factors: briskness, perseverance, sensory sensitivity, emotional reactivity, endurance, and activity. The traits refer to formal characteristics of behaviour encompassed by two basic categories: intensity (energetic aspect of behaviour) and time (temporal aspect of behaviour).

A concept of temperament structures was formulated, which suggests that individual profiles of six traits can be assigned to four distinct structures (types) that differ in terms of stimulation tolerance and ways in which stimulation is regulated (Zawadzki \& Strelau, 2003). The structures are described as follows: 1. Resilient - high stimulation tolerance, effective stimulation regulation (high briskness, sensory sensitivity, endurance, and activity; low emotional reactivity and perseverance); 2. Non resilient - low stimulation tolerance, effective stimulation regulation (low briskness, sensory sensitivity, endurance, and activity; high emotional reactivity and perseverance); 3. Understimulated - high stimulation tolerance, ineffective stimulation regulation (low briskness, sensory sensitivity, activity, emotional reactivity, and perseverance; high endurance); 4. Overstimulated - low stimulation tolerance, ineffective stimulation regulation (high briskness, sensory sensitivity, activity, emotional reactivity, and perseverance; low endurance).

One may expect that the characteristics of temperament profiles such as effectiveness in stimulation regulation and stimulation tolerance can be relevant to risky and health-promoting behaviours by influencing individual tendencies to undertake such behaviours. For example, an overstimulated temperament profile characterised by ineffective stimulation regulation (tendency to overstimulate) and low stimulation tolerance should be associated with a stronger tendency to undertake risky behaviours, while a non-resilient profile characterised by high emotional sensitivity as well as low endurance and activity could be related to health-promoting behaviours. 
The purpose of the present study was to find whether adolescents with different temperament profiles engaged in risky and health-promoting behaviours to varying degrees. A general hypothesis was formulated that there would be differences in reported frequencies of risky and health-promoting behaviours between participants assigned to different temperament profiles on the basis of cluster analysis.

\section{PARTICIPANTS AND PROCEDURE}

Participants were secondary-school students who were recruited at their schools. They were asked to participate voluntarily in the study, which was presented as concerning health habits. There was no gratification associated with participation in the study. A total of 368 students agreed to participate and gave informed consent. After eliminating questionnaires that were not completed properly the sample consisted of 345 students, 196 were female and 149 male, aged 18-19 years. An average of 45 minutes was necessary for participants to answer all questions. The study protocol, information on the study, informed consent, and related materials were submitted and approved considering ethical aspect by the Faculty of Psychology and Education of Silesian University in Katowice. Informed consent was obtained from all participants in the study.

\section{MEASURES}

Temperamental traits were measured with the FCBTI inventory developed by Strelau and Zawadzki (1995, 1993). This is a self-report scale containing 120 items with a yes/no answer format measuring six temperamental traits: briskness, perseverance, sensory sensitivity, emotional reactivity, endurance, and activity. The inventory has good psychometric properties with reliability (Cronbach $\alpha$ ) ranging from .77 to .85 for individual scales. The inventory has also been shown to have high theoretical validity (Strelau \& Zawadzki, 1995).

Frequency of risk behaviours was assessed with a self-report scale containing a list of 31 risky behaviours (i.e. riding a bike without a helmet, crossing a street at a red light). Participants estimated how often they engaged in each behaviour on a five-point scale (very often - often - sometimes - hardly ever never). The list of risk behaviours and the format of answers were based on the Adolescent Risk-Taking Questionnaire (ARQ) developed by Gullone, Moore, Moss, and Boyd (2000). Some behaviours had to be removed from the original scale because they were not relevant in the Polish adolescent population, i.e. flying in a plane. Some risk behaviours were added on the basis of the results of a study in which a group of adolescents were asked to name risk behaviours in which they or their colleagues engaged (Losiak, 2014).

Frequency of health promoting behaviours was assessed with a self-report scale containing a list of 25 behaviours (i.e. caring about personal hygiene, eating fruit and vegetables). Participants estimated how often they engaged in particular behaviour on a fivepoint scale (very often - often - sometimes - hardly ever - never). The behaviours were selected on the basis of the results of the study in which a group of adolescents were asked to name activities relevant to health promotion (Losiak, 2014).

Risk and health behaviours

\section{RESULTS}

Because the majority of participants reported some of the behaviours as occurring rarely or never and analyses of single behaviours did not seem to be appropriate, cumulative indexes of risky and health-promoting behaviours were used. Behaviours to which more than $65 \%$ of participants answered very often, often, or sometimes were used and the aggregated score was calculated. Scores for each behaviour from 1 (never) to 5 (very often) were added and the sum was divided by the number of behaviours. Accordingly, cumulative indexes of risk behaviours and health-promoting behaviours were used in further analyses. It is worth noting here that only four risky behaviours (riding a bike without a helmet, crossing a street at a red light, staying out late, underage drinking) were reported as occurring sometimes, often, or very often by more than $65 \%$ of participants while there were 18 health-promoting behaviours that met this criterion.

Cluster analysis using standardised z-scores of six temperamental traits (FCB-TI scales) was performed in two stages. The first hierarchical cluster analysis (Ward method) was performed, and the means for four clusters were then used as initial cluster centres in a k-means method set for four clusters in order to obtain groups of profiles that could be identified as the four structures described by Zawadzki and Strelau (2003). Cluster centres are given in Table 1. The cluster structure suggested by them was not fully confirmed. While profiles assigned to cluster I can be identified as resilient (high activity, endurance, and briskness) and those in cluster III as non-resilient (high reactivity and perseverance), the other two profiles were different from understimulated or overstimulated structures. Profiles assigned to Cluster II had lower briskness and sensory sensitivity in accordance with understimulated structure; however, they were also characterised by lower endurance and higher activity contrary to the structure described by Zawadzki and Strelau (2003). The profile of traits in Cluster IV was quite similar to the original overstimulated structure (higher briskness, sensory sensitivi- 
ty, perseverance, and activity), but the level of emotional reactivity and endurance was average, while in the original structure the endurance level was low and reactivity high.

An ANOVA with Cluster and Gender as between subjects factors was performed on a cumulative score of risk behaviours. A significant main effect of cluster was observed $(F=3.02, d f=3,344, p=.030)$. Pairwise comparisons revealed that adolescents assigned to Cluster III engaged in risky behaviours less frequently $(M=2.03, S D=0.71)$ than those assigned to Cluster IV $(M=2.40, S D=0.66, p=.010)$. Moreover, participants assigned to Cluster III reported risky behaviours as less frequent than those assigned to Cluster II $(M=2.32, S D=0.66, p=.030)$. There were no significant effects of Gender nor of Cluster x Gender interaction.

The same Cluster $x$ Gender ANOVA was used with cumulative score of health-promoting behaviours as the dependent variable. Significant main effects of Cluster $(F=12.94, d f=3,344, p<.001)$ and Gender $(F=11.37, d f=3,344, p<.001)$ were observed. Pairwise comparisons showed that adolescents assigned to Cluster III engaged in health-promoting behaviours less frequently $(M=2.45, S D=0.44)$ than those assigned to Cluster I $(M=2.76, S D=0.41, p<.001)$, II $(M=2.71, S D=0.37, p<.0001)$, and IV (mean 2.75, $S D=0.34, p<.001)$. Moreover, female participants reported health-promoting behaviours as more frequent $(M=2.73, S D=0.41)$ than male participants $(M=2.58, S D=0.39, p<.001)$. There was no significant effect of Cluster X Gender interaction.

\section{DISCUSSION}

Adolescents with temperamental profiles assigned to different clusters reported engaging in risk and health-promoting behaviours with differing frequency, and thus the hypothesis was generally confirmed.

Participants assigned to Cluster III, who can be identified as having non-resilient temperamental profile, engaged in risky behaviours less frequently than participants assigned to Cluster IV or Cluster II. This result indicates that effective stimulation regulation together with low stimulation tolerance makes a person less inclined to risky behaviours. Similar predictions were formulated in the original model (Zawadzki \& Strelau, 2003). It is very probable that adolescents characterised by low stimulation tolerance engaged in risky behaviours less because such activities were too stimulating.

Moreover, participants assigned to Cluster III (non-resilient temperamental profile) were less inclined to undertake health-promoting behaviours than adolescents with other temperamental profiles. So, the same temperamental profile (low briskness, sensory sensitivity, endurance and activity, high emotional reactivity, and perseverance) that was related with lower frequency of risky behaviours was also related to lower frequency of health-promoting behaviours. While it is difficult to provide an explanation of this result, it is probable that such factors as neuroticism and anxiousness were responsible because such features are related to high emotional reactivity (Strelau, 1993).

It should also be noted that generally adolescents who participated in the study reported more frequent engagement in a greater number of health promoting behaviours (18) than risky behaviours (4). It seems that risk behaviours are not as common in adolescents as might be expected; however, this conclusion should be taken tentatively. Moreover, female participants reported engaging in health promoting behaviours more frequently than male participants.

Generally, the results of the study indicate that temperamental characteristics in the form of individual profiles of traits are significant predictors of not only risk behaviours but also health-promoting behaviours. The differences between adolescents having non-resilient temperamental profile and those having the other three profiles can be attributed to low stimulation tolerance and high emotional reactivity, which are the characteristics related to neurot-

Table 1

Four profiles of temperamental traits (cluster centres, z scores)

\begin{tabular}{lrccc}
\hline Temperament trait & Cluster I & Cluster II & Cluster III & Cluster IV \\
\hline Briskness & .77 & -.19 & -.87 & .30 \\
Perseverance & -1.11 & -.05 & .53 & .48 \\
Sensory sensitivity & -.13 & -1.12 & .26 & .74 \\
Emotional reac- & -1.13 & -.01 & 1.07 & -.01 \\
tivity & 1.05 & -.21 & -.73 & -.04 \\
Endurance & .15 & .21 & -.87 & .51 \\
Activity & & & & \\
\hline
\end{tabular}


icism and anxiousness.

While the study showed that profiles of temperamental traits were related to engaging in risky and health-promoting behaviours, future studies should focus on the identification and characteristics of temperamental profiles. The original four structures described by Zawadzki and Strelau were not fully confirmed in an adolescent sample. Moreover, future studies should include adult participants with different social economic status.

Reported results indicate the role of individual temperamental traits in engaging in risky and health-promoting behaviours and can be useful for school psychologists preparing programmes aimed at prevention of risky behaviours and promotion of healthy behaviours.

There were some limitations of the study. Because it was based on self-reports it is possible that frequencies of risky behaviours were underestimated because participants did not want to report behaviours that are prohibited by the law or generally not approved of. On the other hand, health-promoting behaviours are positively evaluated and recommended, so reported frequencies of such behaviours could be overestimated to some extent. Moreover, the discrepancy between the analysed number of risky and health-promoting behaviours could negatively affect the reliability of cumulative indexes for those behaviours.

\section{References}

Arnett, J. (1990a). Contraceptive use, sensation seeking, and adolescent egocentrism. Journal of Youth and Adolescence, 19, 171-180.

Arnett, J. (1990b). Drunk driving, sensation seeking, and egocentrism among adolescents. Personality and Individual Differences, 11, 541-546.

Beyth-Marom, R., Austin, L.,Fischhoff, B.,Palmgran,C., \& Jacobs-Quadrel, M. (1993). Perceived consequences of risky behaviors: Adults and adolescents. Developmental Psychology, 29, 549-563.

Brejard, V., Bonnett, A., \& Pedinielli, J. L. (2012). Role du temperament et de la conscience emotionalle dans la prise de risqué chez des adolescents. L'encephale, 38, 1-9.

Caspi, A., Begg, D., Dickson, N., Harrington, H. L., Langley, J., Moffitt, T. E., \& Silva, A. (1997). Personality Differences Predict Health-Risk Behaviors in Young Adulthood: evidence From a Longitudinal Study. Journal of Personality and Social Psychology, 73, 1052-1063.

Cooper, M. L., Wood, P. K., Orcutt, H. K., \& Albino, A. (2003). Personality and the predisposition to engage in risky or problem behaviors during adolescence. Journal of Personality and Social Psychology, 84, 390-410.
Feldstein, S. W., \& Miller, W. R. (2006). Substance use and risk-taking among adolescents. Journal of Mental Health, 15, 633-643.

Gullone, E., Moore, S., Moss, S., \& Boyd, C. (2000). The Adolescent Risk-Taking Questionnaire: Development and Psychometric Evaluation. Journal of Adolescent Research, 15, 231-250.

Losiak, J. (2014). Zachowania prozdrowotne i ryzykowne mtodzieży u progu dorosłości oraz ich poznawcze i temperamentalne wyznaczniki [Health promoting and risk behaviors in young adults and their cognitive and temperamental correlates]. (Unpublished doctoral thesis). Silesian University, Katowice.

Maslowsky, J., Buvinger, E., Keating, D. P., Steinberg, L., \& Cauffman, E. (2011). Cost-benefit analysis mediation of the relationship between sensation seeking and risk behavior among adolescents. Personality and Individual Differences, 51, 802-806.

Pisarek, A., Guszkowska, M., Zagórska, A., \& Lenartowicz, M. (2011). Characteristics of athletes' approach to the question of physical health and health behaviors: Do athletes lead healthy lifestyles? Journal of Applied Sport Psychology, 23, 459-473.

Rudasill, K. M., Reio, T. G., Stipanovic, N., \& Taylor, J. E. (2010). A longitudinal study of student-teacher relationship quality, difficult temperament, and risky behavior from childhood to early adolescence. Journal of School Psychology, 48, 389-412.

Stevens, E., Plumert, J. M., Cremer, J. F., \& Kearney, J. K. (2013). Preadolescent temperament and risky behavior: bicycling across traffic-filled intersections in a virtual environment. Journal of Pediatric Psychology, 38, 285-295.

Strelau, J. (1993). The location of the Regulative Theory of Temperament (RTT) among other temperament theories. In J. Hettema \& I. J. Deary (eds.), Foundations of Personality (pp. 113-132). Dordrecht: Kluwer.

Strelau, J., \& Zawadzki, B. (1993). The Formal Characteristics of Behaviour - Temperament Inventory (FCB-TI): theoretical assumptions and scale construction. European Journal of Personality, 7, 313-336.

Strelau, J., \& Zawadzki, B. (1995). The Formal Characteristics of Behaviour - Temperament Inventory (FCB-TI): validity studies. European Journal of Personality, 9, 207-229.

Virgo-Milton, M., Boak, R., Hoare, A., Gold, L., Waters, E., Gussy, M., ...de Silva, A. M. (2015). An exploration of the views of Australian mothers on promoting child oral health. Australian Dental Journal. doi: 10.1111/adj.12332

White, T. L., Lejuez, C. W., \& de Wit, H. (2007). Personality and Gender Differences in Effects of $\mathrm{d}$-Amphetamine on Risk Taking. Experimental and Clinical Psychopharmacology, 15, 599-609.
Risk and health behaviours 
Yucel, M., Whittle, S., Youssef, G., Kashyap, H., Simmons, J., Schwartz, O., Lubman, D., \& Allen, N. (2015). The influence of sex, temperament, risk-taking and mental health on the emergence of gambling: a longitudinal study of young people. International Gambling Studies, 15, 108-123.

Zawadzki, B., \& Strelau, J. (2003). Trzy podstawowe typy czy cztery struktury temperamentu? [Three basic types or four structures of temperament?]. Czasopismo Psychologiczne, 9, 271-285.

Julia Łosiak-Pilch 